\title{
CT-Guided Nucleoplasty: Preliminary Experience
}

\author{
Tilman Wolter ${ }^{1}$, Mohsen Mohadjer', Stefan M. Knoeller', Ansgar Berlis²
}

\begin{abstract}
Introduction
In the last years, nucleoplasty has become a standard treatment for low back pain and radicular pain due to disk protrusion. Some authors have reported favorable results with success rates between $70 \%$ and $80 \%$ [1-5]. Others have pointed out preliminary positive experiences with this new technique without significant adverse effects [6]. Marin published a series of 51 patients with pain improvement in $80 \%$ of the patients at 6 - to 12 -month follow-up. None of these patients deteriorated [2].

Also the first randomized study of nucleoplasty which was recently published by Nardi et al. supports these findings. $80 \%$ of the 50 patients treated with cervical nucleoplasty had complete resolution of the symptoms. In $10 \%$ of the patients, there still was some residual (radicular) pain [7].

In 2005, however, Boswell et al. stated that there was limited evidence for nucleoplasty in managing lumbar discogenic pain [8]. Recently, Freeman \& Mehdian reported that there are no published randomized controlled trials assessing coblation technology (nucleoplasty) [9].

In a study on human cadavers, intradiscal pressure was markedly reduced in the younger, healthy disk cadaver. In the older, degenerative disk cadavers, the change in intradiscal pressure after nucleoplasty was very small. There was an inverse correlation between the degree of disk degeneration and the change of intradiscal pressure [10].

In most of the cases, nucleoplasty is performed under fluoroscopic control in general anesthesia or in mild sedation. Planning of the trajectory is done with the help of Kambin's triangle (Figure 1) [11]. This, however, still carries the risk of unadverted damage to the nerve root, which then due to general anesthesia cannot be noticed by the surgeon.
\end{abstract}

Alexandre et al. pointed out that principal risks are damage to the root along with puncture and conduction of the electrical stimulus when the spine wand is not perfectly located (besides the risks of perforation of vessels and of infection) [3]. General anesthesia is often used for two reasons. On the one hand, surely the perforation of the anulus fibrosus, on the other hand, unintentional, even slight contact to the nerve root is painful.

The frequency of nerve root damage during nucleoplasty remains unclear. Gerszten et al. described no nerve root injuries in a series of 67 patients [12] whereas Bhagia et al. observed new numbness and tingling in $26 \%$ and new areas of back pain in $15 \%$ of 53 patients [13] which, from our point of view, hint at nerve root damage. However, it can be assumed that some patients encounter damage to the nerve root during nucleoplasty. In a recent review about complications of intradiscal procedures, it is stated that "there is no evidence to suggest that there is a higher complication rate associated with the use of this largebore introducer. Nonetheless, it stands to reason that use of a larger needle may well lead to greater neural injury in the event of contact with a neural structure" [14]. The introducer used in nucleoplasty is 17 gauge whereas the needle typically used in discography is $22-25$ gauge.

Theoretically, the risk of nerve root damage could be reduced by performing the procedure under computed tomography (CT) guidance. The purpose of this retrospective study was to determine if CT-guided nucleoplasty is feasible.

\section{Patients and Interventions}

Nine patients (seven male, two female) with a median age of 37.9 years (16-59 years) were treated. The anamnesis was recorded and a pain analysis and clinical ex-

'Interdisciplinary Pain Center, University Hospital Freiburg, Germany, ${ }^{2}$ Department of Neuroradiology, University Hospital Freiburg, Germany. 


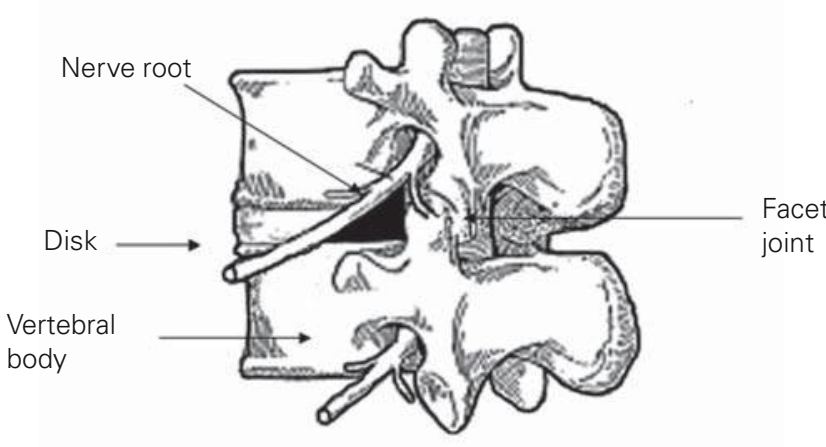

Figure 1. Kambin's triangle: the black triangle represents the zone in which the disk can be entered without risk of nerve root damage (modified from [11]).

amination were carried out at the Interdisciplinary Pain Center, University Hospital Freiburg, Germany. All patients from low back pain and four patients suffered from additional radicular pain (Table 1 ). In all patients, pain had been lasting for a period of at least 3 months and it had been refractory to physiotherapy and analgetic medication.

Magnetic resonance (MR) and CT examinations showed lumbar disk protrusion in all patients. Written informed consent was obtained prior to the procedure.

For planning of the trajectory, the whole disk was examined in the multislice CT scanner (Siemens Medical Solutions, type Somatom Sensation 16). After identification of the nerve root, the trajectory was defined (Figure 2). After disinfection and sterile draping, nucleoplasty was performed in local anesthesia of the skin with $5 \mathrm{ml}$ xylocaine $2 \%$. The 17 -gauge, 6 -inch Crawford needle (Arthro Care Spine, Inc., Sunnyvale, CA, USA) was placed at the point marked before and inserted according to the preassigned trajectory. When the annulus was reached, a CT scan verified the correct position of the cannula (Figure 3 ). In some patients, $1-2 \mathrm{ml}$ of local anesthetic was applied in order to reduce the pain caused by penetration of the anulus fibrosus. After positioning of the cannula inside the disk, a further CT scan was performed to assure the optimal position of the nucleoplasty device. From this scan the distance from the needle tip to the contralateral margins of the disk could be measured, in order to securely avoid ventral perforation (Figure 4). Finally, the spine wand (ArthroCare Spine, Inc.) was inserted and nucleoplasty was performed creating six to eight channels turning the nucleoplasty de-

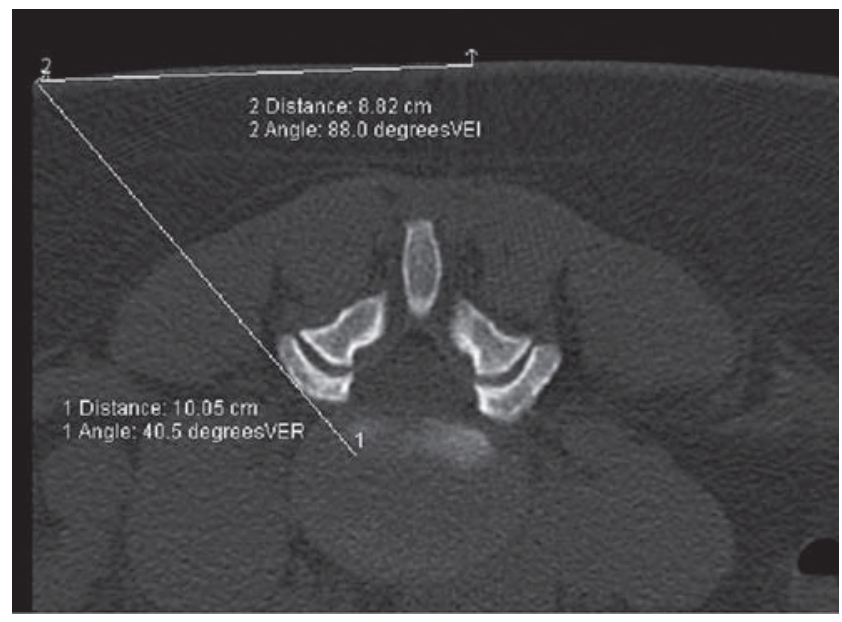

Figure 2. Calculation of the trajectory.

vice clockwise. A postprocedural CT scan of the whole disk verified the amount of tissue reduction (Figure 5) and excluded side effects like hemorrhage. Outpatient follow-up was at 6 weeks and 6 months post procedure and included a clinical examination and pain analysis.

\section{Results}

All of the nine patients treated had disk protrusions at the L $4 / 5$ level. Injury to the nerve root did not occur. All patients reported at least partial pain relief directly after the procedure. At 6-week follow-up, four patients were free of pain, two patients showed constant but significantly reduced pain, and three patients suffered from recurrent pain. At 6-month follow-up, two patients were free of pain, one patient had constant significant pain reduction. These patients were back at work. Six patients had recurrent pain (Table 1).

None of the patients had signs of radicular damage like occurrence of new radicular pain, numbness, motor deficit or causalgia during or secondary to the procedure.

Mean duration of symptoms before nucleoplasty in the three patients with excellent or good outcome was 28.6 months, in those patients who had no benefit it was 79.8 months.

\section{Discussion}

Nucleoplasty seems to be indicated when lumbar disk protrusion causes either low back pain by compression of the posterior longitudinal ligament or radicular pain by compression of the adjacent nerve root, or in a combination of both. Sequestrated prolapses are not suit- 


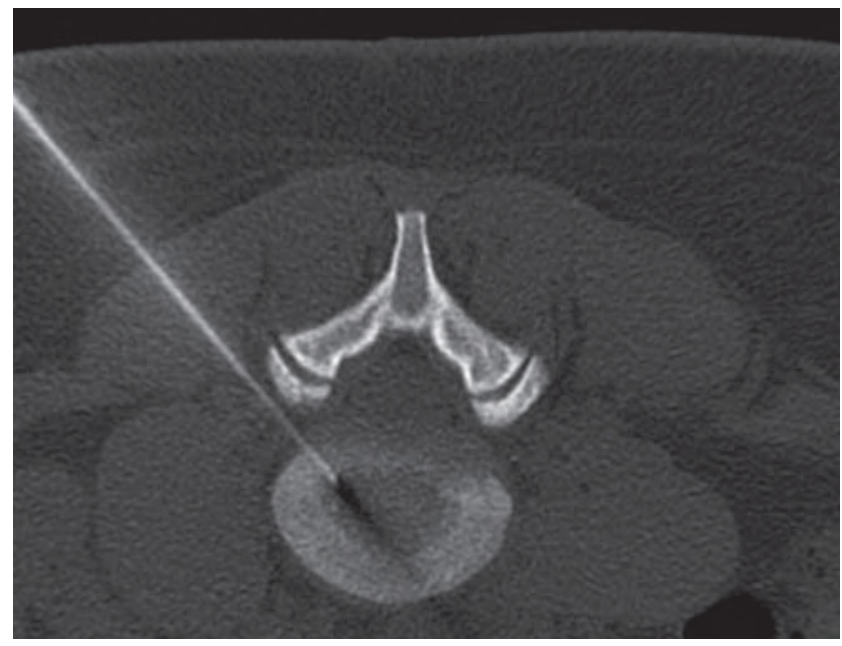

Figure 3. Positioning of the cannula.

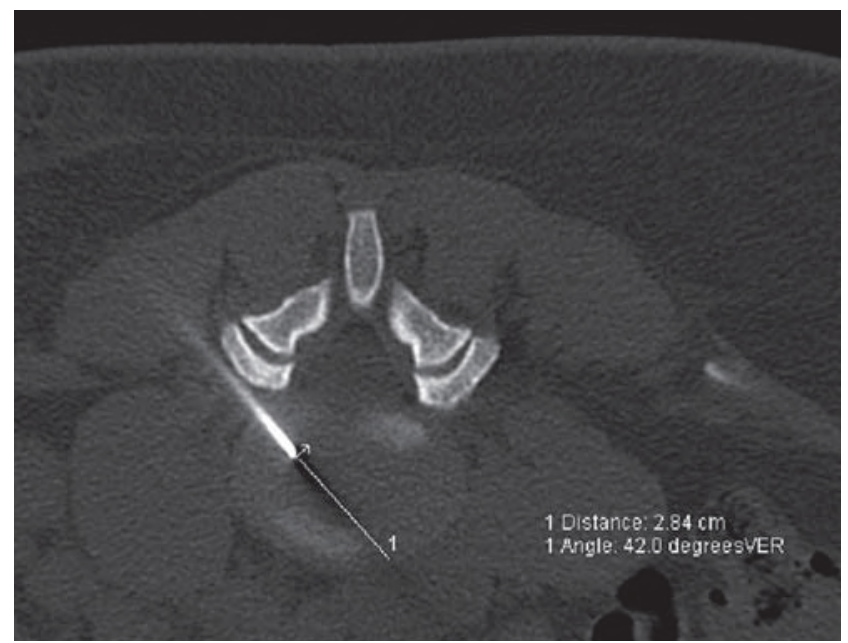

Figure 4. Calculation of the remaining intradiscal distance after positioning of the cannula.
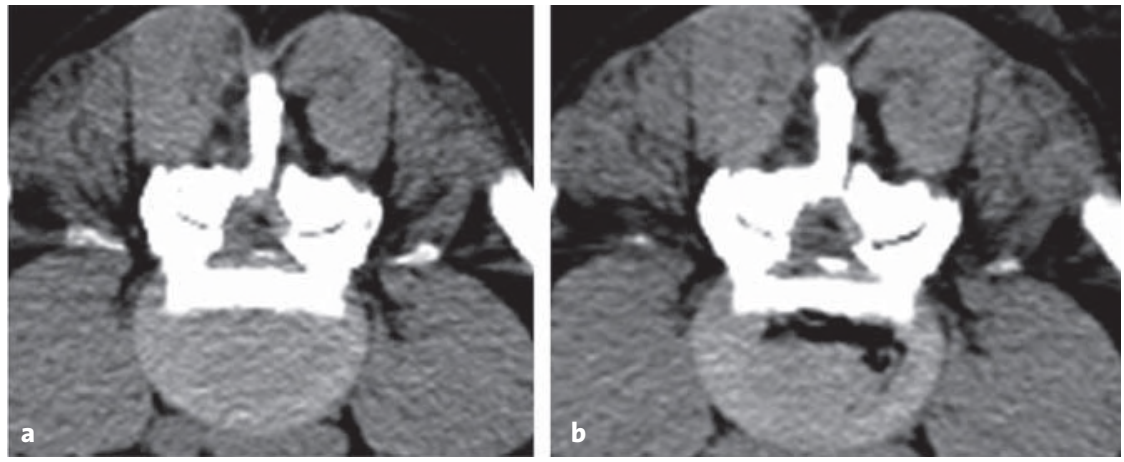

Figure 5. Lumbar disk L4/5 a) before and b) immediately after CT-guided nucleoplasty.

Table 1. Patient data regarding pain characteristics (LBP: low back pain, $L_{5}$ : radicular pain in the L5 dermatome). Outcome at 6-week and 6-month follow-up and preinterventional pain duration. Excellent: total resolution of clinical picture and full resumption of daily activities; good: fairly total resolution of pain with rather good quality of life; scanty: insignificant pain resolution and inability to take up normal daily activities; none: no results both on pain and clinical field. F: female; $M$ : male.

\begin{tabular}{|c|c|c|c|c|c|}
\hline Sex & $\begin{array}{l}\text { Age } \\
\text { (years) }\end{array}$ & $\begin{array}{l}\text { Preinterven- } \\
\text { tional }\end{array}$ & $\begin{array}{l}\text { 6-week follow-up } \\
\text { pain/dermatome }\end{array}$ & 6-month follow-up & $\begin{array}{l}\text { Preinterventional } \\
\text { duration of pain } \\
\text { (months) }\end{array}$ \\
\hline M & 49 & LBP > L5 left & Excellent & Scanty & 156 \\
\hline M & 43 & LBP & Excellent & Scanty & 21 \\
\hline M & 16 & LBP & Excellent & Scanty & 5 \\
\hline M & 33 & bilateral L5 = LBP & Scanty & None & 108 \\
\hline $\mathrm{F}$ & 35 & L4 right > LBP & Excellent & Excellent & 7 \\
\hline $\mathrm{F}$ & 29 & LBP & Scanty & Scanty & 168 \\
\hline M & 36 & LBP & None & None & 21 \\
\hline M & 59 & LBP > L5 left & Good & Good & 33 \\
\hline M & 41 & LBP & Excellent & Excellent & 46 \\
\hline
\end{tabular}

able for nucleoplasty because a reduction of intradiscal pressure does not influence the position of the sequestrated prolapse. Conservative therapy should have been performed for at least 3 months.

Pain reduction in our study is considerably worse than in other studies. This was probably due to patient selection rather than to the targeting technique. Our institution is a national academic pain center and most of our low back pain patients are suffering from highly chronic complaints often complicated by depression and/or anxiety disorders. Patients in the series of Marin had a mean duration of pain of 18 months. After treatment, $80 \%$ of the cases showed a good or very good improvement in pain scores [2]. In our study, mean duration of pain was 28.6 months in the group of patients who had a good pain relief and 79.8 months in those patients who did not benefit from the procedure. Yakovlev et al. published a series of 22 patients in which mean pain scores decreased for $54.5 \%, 72.7 \%$, $72.7 \%$, and $72.7 \%$ of patients at $1-$, 3-, 6-, and 12-month follow-up, re- 
spectively. In this study, history of alcohol or drug abuse was significantly associated with a poor outcome [15]. Previously, in a study of patients following minimally invasive diskectomy, a history of alcohol and drug abuse, psychological distress, and depression had been associated with poorer outcomes [16].

Though these observations are not statistically significant, they do at least hint at an inverse correlation between duration of symptoms and outcome after nucleoplasty and may give an explanation of the relatively poor outcomes in our patients.

Performing nucleoplasty under conditions of CT guidance has a couple of advantages. The risk of nerve root damage might be apparently lower than under fluoroscopic guidance, because the CT scan allows a safe approach after secure identification of the nerve root. Although the insertion of the cannula along the trajectory cannot be observed in real time, intraprocedural CT scans allow that the needle does not affect the nerve root. Moreover, they can demonstrate the close relationship of the needle and the annulus. This allows exact application of small amounts of local anesthetics to reduce the intensity of pain during perforation of the annulus which otherwise would make either general or at least short-term anesthesia necessary.

Under CT guidance a more precise designation of the target point of the needle and of the nucleoplasty device is possible. Moreover, the CT examination of the disk allows to closely assess the amount of tissue reduction achieved during the procedure.

The use of a CT scanner monitor directly be aside the patient table prevents a time-consuming procedure. Of course not every center performing nucleoplasty will be in a position to offer CT guidance for nucleoplasty. If both methods, fluoroscopic and CT guidance are available, CT guidance might be a favorable alternative to avoid iatrogenic damage and ensure high treatment quality.

\section{Conflict of Interest Statement}

The authors declare that there is no actual or potential conflict of interest in relation to this article.

\section{References}

1. Singh V, Piryani C, Liao K. Role of percutaneous disc decompression using coblation in managing chronic discogenic low back pain: a prospective, observational study. Pain Physician 2004;7:419-25.
2. Marin FZ. CAM versus nucleoplasty. Acta Neurochir Suppl (Wien) 2005; 92:111-4.

3. Alexandre A, Coro L, Azuelos A, Pellone M. Percutaneous nucleoplasty for discoradicular conflict. Acta Neurochir Suppl (Wien) 2005;92: 83-6.

4. Reddy AS, Loh S, Cutts J, Rachlin J, Hirsch JA. New approach to the management of acute disc herniation. Pain Physician 2005;8:385-90.

5. Sharps LS, Isaac Z. Percutaneous disc decompression using nucleoplasty. Pain Physician 2002;5:121-6.

6. Welch WC, Gerszten PC. Alternative strategies for lumbar discectomy: intradiscal electrothermy and nucleoplasty. Neurosurg Focus 2002;13:E7.

7. Nardi PV, Cabezas D, Cesaroni A. Percutaneous cervical nucleoplasty using coblation technology. Clinical results in fifty consecutive cases. Acta Neurochir Suppl (Wien) 2005;92:73-8.

8. Boswell MV, Trescot AM, Datta S, Schultz DM, Hansen HC, Abdi S, Sehgal N, Shah RV, Singh V, Benyamin RM, Patel VB, Buenaventura RM, Colson JD, Cordner HJ, Epter RS, Jasper JF, Dunbar EE, Atluri SL, Bowman RC, Deer TR, Swicegood JR, Staats PS, Smith HS, Burton AW, Kloth DS, Giordano J, Manchikanti L, American Society of Interventional Pain Physicians. Interventional techniques in the management of chronic spinal pain: evidence-based practice guidelines. Pain Physician 2005;8:1-47.

9. Freeman BJ, Mehdian R. Intradiscal electrothermal therapy, percutaneous discectomy, and nucleoplasty: what is the current evidence? Curr Pain Headache Rep 2008;12:14-21.

10. Chen YC, Lee SH, Chen D. Intradiscal pressure study of percutaneous disc decompression with nucleoplasty in human cadavers. Spine 2003;28:661-5.

11. Kambin P. Arthroscopic microdiskectomy. Mt Sinai J Med 1991;58: 159-64.

12. Gerszten PC, Welch WC, King JT Jr. Quality of life assessment in patients undergoing nucleoplasty-based percutaneous discectomy. J Neurosurg Spine 2006;4:36-42.

13. Bhagia SM, Slipman CW, Nirschl M, Isaac Z, El-Abd 0, Sharps LS, Garvin C. Side effects and complications after percutaneous disc decompression using coblation technology. Am J Phys Med Rehabil 2006;85:6-13.

14. Rathmell JP, Saal JS, Saal J. Discography, IDET, percutaneous discectomy, and nucleoplasty: complications and their prevention. Pain Med 2008;9:73-81.

15. Yakovlev A, Tamimi MA, Liang H, Eristavi M. Outcomes of percutaneous disc decompression utilizing nucleoplasty for the treatment of chronic discogenic pain. Pain Physician 2007;10:319-28.

16. Carragee EJ. Psychological screening in the surgical treatment of lumbar disc herniation. Clin J Pain 2001;17:215-9.

\author{
Address for Correspondence \\ Tilman Wolter, MD \\ Interdisciplinary Pain Center \\ University Hospital Freiburg \\ Breisacher Straße 64 \\ 79106 Freiburg \\ Germany \\ Phone $(+49 / 761)$ 270-5020, Fax -5013 \\ e-mail:tilman.wolter@uniklinik-freiburg.de
}

